\title{
S-methyl-L-cysteine Protects against Antimycin A-induced Mitochondrial Dysfunction in Neural Cells via Mimicking Endogenous Methionine-centered Redox Cycle*
}

\author{
Lan $\mathrm{NI}^{1,3,4}$, Xin-lei GUAN ${ }^{1,2}$, Fu-feng $\mathrm{CHEN}^{1}$, Peng-fei WU ${ }^{1,3,4 \#}$ \\ ${ }^{1}$ Department of Pharmacology, School of Basic Medicine, Tongji Medical College, Huazhong University of Science and \\ Technology, Wuhan 430030, China \\ ${ }^{2}$ Department of Pharmacy, Wuhan Puai Hospital, Tongji Medical College, Huazhong University of Science and Technology, \\ Wuhan 430033, China \\ ${ }^{3}$ Tongji-Rongcheng Center for Biomedicine, Wuhan 430030, China \\ ${ }^{4}$ Key Laboratory for Drug Target Researches and Pharmacodynamic Evaluation of Hubei Province, Wuhan 430030, China
}

(C) The Author(s) 2020

\begin{abstract}
Summary: Mitochondrial superoxide overproduction is believed to be responsible for the neurotoxicity associated with neurodegeneration. Mitochondria-targeted antioxidants, such as MitoQ, have emerged as potentially effective antioxidant therapies. Methionine sulfoxide reductase A (MsrA) is a key mitochondrial-localized endogenous antioxidative enzyme and it can scavenge oxidizing species by catalyzing the methionine (Met)-centered redox cycle (MCRC). In this study, we observed that the natural L-Met acted as a good scavenger for antimycin A-induced mitochondrial superoxide overproduction in PC12 cells. This antioxidation was largely dependent on the Met oxidase activity of MsrA. S-methyl-L-cysteine (SMLC), a natural analogue of Met that is abundantly found in garlic and cabbage, could activate the Met oxidase activity of MsrA to scavenge free radicals. Furthermore, SMLC protected against antimycin A-induced mitochondrial membrane depolarization and alleviated 1-methyl-4-phenylpyridinium $\left(\mathrm{MPP}^{+}\right)$-induced neurotoxicity. Thus, our data highlighted the possibility for SMLC supplement in the detoxication of mitochondrial damage by activating the Met oxidase activity of MsrA.

Key words: methionine sulfoxide reductase A; Met oxidase; S-methyl-L-cysteine; neurotoxin; 1-methyl-4-phenylpyridinium
\end{abstract}

Reactive oxygen species (ROS), especially the free radicals, are implicated in the toxic mechanism of neurotoxins, including rotenone ${ }^{[1-3]}$, lipopolysaccharide $^{[4]}$ and 1-methyl-4-phenylpyridinium $\left(\mathrm{MPP}^{+}\right)^{[5]}$, etc. Mitochondria are key cell organelles that control many processes by maintaining energy production. To produce energy, the mitochondrial electron transport chain is coupled with the production of ROS, such as superoxide anion or hydrogen peroxide. Mitochondrial superoxide overproduction is considered to be the major factor in oxidative toxicity

Lan NI, E-mail: 295651003@qq.com

\#Corresponding author, E-mail: wupengfeipharm@foxmail. com

${ }^{*}$ This work was supported by grants from the National Natural Science Foundation of China (No. 81773712, No. 81473198), the Foundation for Innovative Research Groups of NSFC (No. 81721005), the National Basic Research Program of China (973 Program, No. 2014CB744601), Science Fund for Creative Research Groups of the Natural Science Foundation of Hubei Province (No. 2015CFA020) and PCSIRT (No. IRT13016). associated with neurodegeneration. Mitochondriatargeted antioxidants, such as MitoQ and mitotempo, have emerged as potentially effective antioxidant therapies ${ }^{[-8]}$. However, mounting evidence indicates that the mitochondrial ROS are related with multiple essential cellular functions ${ }^{[9,10]}$ and these mitochondriatargeted antioxidants may disrupt physiological signaling ${ }^{[11,12]}$.

As a result of the constant production of ROS, mitochondria are protected by various antioxidant systems, such as glutathione reductase, thioredoxin reductase and manganese superoxide dismutase ${ }^{[13]}$. These antioxidant systems only diminish overproduced mitochondrial ROS, but not affect ROS signaling apt for physiological signaling. The thiomethyl group that exists on the surface exposed methionine (Met) residues has been recognized as a key endogenous antioxidant defense ${ }^{[14-17]}$. Methionine in proteins is often thought to be a generic hydrophobic residue on the surface. A variety of ROS react with Met residues to form methionine sulfoxide (MetO), which is followed by MetO reductases-mediated reduction back to Met, 
named Met-centered redox cycle $(\mathrm{MCRC})^{[15,17]}$. As a key member of MetO reductases, MetO reductase A (MsrA) has been reported to be abundantly localized in the mitochondrion ${ }^{[18-20]}$. MsrA repairs oxidative damage of proteins and increases resistance of cells against many toxins, including zinc, hydrogen peroxide, 6-hydroxydopamine and acetaminophen ${ }^{[21-25]}$. MsrA also reduces mitochondrial ROS levels in response to insults ${ }^{[24,26]}$ and protects mitochondrial dysfunctions in a mouse model of Alzheimer's disease (AD) ${ }^{[27]}$. Although its action via repairing oxidized proteins is easily accepted, the mechanism by which MsrA scavenges ROS remains largely elusive. MsrA has historically been considered a reductase, not an ROS scavenger, for the reaction of Met with oxidizing species was widely viewed as a natural process. Recent studies from our lab have indicated that the antioxidant capability of MsrA may involve a Met oxidase activity that facilities the reaction of Met with ROS, which may underlie the effect of MsrA on neuroinflammation and lifespan ${ }^{[28,29]}$.

Exogenous substrates like L-methionine (L-Met) could activate the Met oxidase activity ${ }^{[29]}$, but dietary supplementation with L-Met is not applicable for mitochondrial dysfunction, because Met is rapidly incorporated into protein or metabolized, and high dietary Met intake confers an increased risk of acute coronary events in patients with cardiovascular diseases $^{[30,}{ }^{31]}$. S-methyl-L-cysteine (SMLC) is a hydrophilic cysteine-containing compound naturally found in Alium plants such as garlic and onion ${ }^{[32]}$. Previous studies reported its safety and benefits, including no adverse effect and toxicity in mammals, lowering of the serum cholesterol level, a delay in diabetes pathogenesis and prevention in PD symptoms $^{[33-36]}$. Furthermore, SMLC has been revealed as a substrate in the catalytic antioxidant system mediated by $\mathrm{MsrA}^{[36]}$. In the present study, we found that SMLC protected against antimycin A-induced mitochondrial dysfunction in neural cells via activating Met oxidase activity of MsrA and mimicking endogenous Met-centered redox cycle.

\section{MATERTALS AND METHODS}

\subsection{Chemicals and Materials}

Dulbecco's modified Eagle's medium (DMEM), horse serum, fetal bovine serum and G418 were purchased from Gibco Invitrogen Corporation (USA). Trypsin, 5,5-dimethyl-1-pyrroline-N-oxide (DMPO) and 3-(4,5-dimethylthiazol-2-yl)-2,5-diphenyltetrazolium bromide (MTT) were obtained from Sigma-Aldrich (USA). Plasmid containing rat MsrA cDNA (pcDNA3.1rMsrA) was provided courtesy of Dr. Bertrand Friguet of the Université Paris 7-Denis Diderot. L-Met, SMLC and dithiothreitol (DTT) were purchased from
Sigma-Aldrich (USA). All the other reagents were of analytical grade. Amicon ultra-4 centrifugal filter devices were purchased from Millipore Carrigtwohill, Co. Cork (Ireland). $\mathrm{H}_{2} \mathrm{O}_{2}$ was purchased from Merck (Germany). All the chemicals were dissolved in water to make individual stock solutions, depending upon their water solubility, and stored at $-20^{\circ} \mathrm{C}$. Other general agents were available commercially. Distilled water was deionized in a Milli-Q SP reagent water system (Millipore, USA).

\subsection{Preparation of Rat Recombined MsrA}

The rat recombined MsrA was prepared and purified from $E$. coli BL21, as described in our previous report $^{[37]}$. In brief, MsrA coding region was ligated into the restricted pET-32a $(+)$ vector using phage T4 DNA ligase, and BL21 cells were transformed with the recombinant plasmid and grown in LB medium. The cells were harvested, and applied to a Ni-Trap nickel-chelating column. The N-terminal His-tag of recombinant protein was removed using a Thrombin kit. The activity of recombinant MsrA was monitored by detecting both total MetO reducing activity and methyl sulfoxide-initiated oxidation of DTT.

\subsection{Electron Paramagnetic Resonance (EPR)}

EPR was performed as described in our previous reports with some modifications ${ }^{[28,29]}$. DMPO was used as a free radical trapper. EPR signals were detected with a Bruker e-scan EPR spectrometer (Burker, Germany). We produced hydroxyl radical $(\mathrm{OH} \cdot)$ by the Fenton reaction in the mixture of $0.25 \mathrm{mmol} / \mathrm{L} \mathrm{H}_{2} \mathrm{O}_{2}$ and 0.1 $\mathrm{mmol} / \mathrm{L} \mathrm{FeSO}_{4}$ in the presence of $0.1 \mathrm{mmol} / \mathrm{L}$ DMPO. The spin traps, L-Met $(0.1$ or $1 \mathrm{mmol} / \mathrm{L})$, SMLC $(0.1,1$ or $10 \mathrm{mmol} / \mathrm{L})$ and $\mathrm{rMsrA} /$ non-active $\mathrm{rMsrA}$ ( $1 \mu \mathrm{mol} / \mathrm{L}$ ) were added before the Fe (II) and $\mathrm{H}_{2} \mathrm{O}_{2}$. Samples $(20 \mu \mathrm{L})$ were loaded into a quartz tube and the EPR spectra were recorded at room temperature. The EPR microwave power was set at $4.88 \mathrm{~mW}$. The modulation frequency was $9.76 \mathrm{GHz}$. The time constant was $81.92 \mathrm{~ms}$. The conversion time was 81.92 $\mathrm{ms}$ and a sweep time of $41.94 \mathrm{~s}$ was used. Each sample was scanned once. A sweep width of $100 \mathrm{G}$ was used for experiments with DMPO. The receiver gain was set at $3.17 \times 10^{3}$. Simulation and fitting of the EPR spectra were performed using the Bruker WinEPR program.

\subsection{Cell Cultures and Treatment Paradigm}

Cells were cultured as described in our previous reports with slight modifications ${ }^{[37,38]}$. Rat PC12 cells were obtained from Chinese Type Culture Collection and have been differentiated to be neuron-like by treating with nerve growth factor. PC12 cells were cultured in DMEM containing 5\% heat-inactivated fetal calf serum, $10 \%$ heat-inactivated horse serum, $100 \mu \mathrm{g} / \mathrm{mL}$ streptomycin and $100 \mathrm{U} / \mathrm{mL}$ penicillin in a humidified atmosphere of $95 \%$ air and $5 \% \mathrm{CO}_{2}$ at $37^{\circ} \mathrm{C}$. The culture medium was changed and the cells were passaged by trypsinization every 3 to 4 days. For 
oxidative stress, cells were rinsed twice with PBS and subjected to $\mathrm{H}_{2} \mathrm{O}_{2}(250 \mu \mathrm{mol} / \mathrm{L})$ in DMEM. Different concentrations of L-Met were added to the culture medium $12 \mathrm{~h}$ prior to oxidative stress until the end of $\mathrm{H}_{2} \mathrm{O}_{2}$ treatment.

The human dopamine neuronal cell line, SH-SY5Y, was obtained from Cell Centre of Chinese Academy of Medical Sciences (China) and cryopreserved after subculturing various passages. Each subculture was limited to no more than 10 passages. SH-SY5Y cells (passages 30-40) were cultured in DMEM/F12 medium containing $10 \%$ heat-inactivated FBS, $50 \mathrm{U} / \mathrm{mL}$ penicillin and $50 \mathrm{mg} / \mathrm{mL}$ streptomycin in a humidified atmosphere of $95 \%$ air and $5 \% \mathrm{CO}_{2}$ at $37^{\circ} \mathrm{C}$. Medium was changed every 2 days, and cells were passaged at $80 \%$ confluence every 3-4 days. In the experiments, cells were synchronized at the G0 phase by serum deprivation. Different concentrations of L-Met and SMLC in DMEM/F12 medium without FBS were used to treat SH-SY5Y cells for $12 \mathrm{~h}$. After preconditioning, a final concentration of $\mathrm{MPP}^{+}(2 \mathrm{mmol} / \mathrm{L})$ was used to treat SH-SY5Y cells for $48 \mathrm{~h}$. $\mathrm{MPP}^{+}$treatments were performed in DMEM/F12 medium without FBS under dark condition to avoid photo-catalytic decomposition reaction.

\subsection{ROS Staining}

The total intracellular ROS were determined by the MitoSOX red assay. In brief, PC12 cells were seeded in a 6-well plate and loaded with MitoSOX red (Invitrogen, USA) for $1 \mathrm{~h}$, which was followed by pretreatment with L-Met $(0.1,0.5$, and $1 \mathrm{mmol} / \mathrm{L})$ or SMLC $(0.1,0.5$, and $1 \mathrm{mmol} / \mathrm{L})$ for $30 \mathrm{~min}$, and then treatment with antimycin A $(100 \mathrm{ng} / \mathrm{mL})$ (SigmaAldrich, USA). After incubation at $37^{\circ} \mathrm{C}$ for $30 \mathrm{~min}$, the fluorescence images were immediately taken using a fluorescence microscope (System Microscopy IX70; Olympus, Japan). For the detection of cellular superoxide, we used $5 \mu \mathrm{mol} / \mathrm{L}$ MitoSOX (Invitrogen, USA), and took images using excitation and emission filters of 543 and $565 \mathrm{~nm}$, respectively. Fluorescent signals intensities of cells were obtained using ImagePro Plus (IPP) software.

\subsection{Construction of Short Hairpin RNA (shRNA)} Lentiviral Expression Vector and MsrA Knockdown

shRNA lentiviral expression vector was constructed as described in our previous reports with some modifications ${ }^{[29]}$. A third generation of selfinactivating lentivirus vector (GeneChem, China) containing a CMV-driven GFP reporter and a U6 promoter upstream of the cloning sites (EcoR I and Age I) was used for cloning MsrA shRNA. The target sequence for control scrambled shRNA was 5'-TTCTCCGAACGTGTCACGT-3' and rat MsrA was 5'-AGCACGTCAGCTTTGAGGA-3'. PC12 cells were infected with lentivirus at a multiplicity of infection (MOI) of 20 for $10 \mathrm{~h}$. Then, the medium was replaced with fresh complete medium. After $72 \mathrm{~h}$, cells were observed under the fluorescence microscope to confirm that more than $80 \%$ of cells were GFPpositive. The knockdown of MsrA was evaluated by Western blotting.

\subsection{Mitochondrial Membrane Potential}

To determine the mitochondrial membrane potential, PC12 cells were seeded in a 6-well plate and incubated with $2 \mu \mathrm{g} / \mathrm{mL} \mathrm{JC}-1$ at $37^{\circ} \mathrm{C}$ for $30 \mathrm{~min}$, which was followed by pretreatment with L-Met $(1 \mathrm{mmol} / \mathrm{L})$ or SMLC $(1 \mathrm{mmol} / \mathrm{L})$ for $30 \mathrm{~min}$, and then treatment with antimycin A $(100 \mathrm{ng} / \mathrm{mL})$. After incubation at $37^{\circ} \mathrm{C}$ for $30 \mathrm{~min}$, cells were then washed twice with PBS and immediately examined by fluorescence spectrometry using a fluorescence microplate reader (System Microscopy IX70; Olympus, Japan). A 488 $\mathrm{nm}$ filter was used for excitation of JC-1, and emissions at 535 and $595 \mathrm{~nm}$ were used to quantify the population of mitochondria with green (JC-1 monomers) and red (JC-1 aggregates) fluorescence respectively. The $\mathrm{red} /$ green ratio was used to reflect the mitochondrial membrane potential.

\subsection{MTT Assay}

Cell viability was measured by MTT assay based on the conversion of MTT to formazan crystals by mitochondrial dehydrogenases. In live cells, mitochondrial enzymes have the capacity to transform MTT to insoluble formazan. Cell cultures were incubated with MTT solution $(5 \mathrm{mg} / \mathrm{mL})$ for $4 \mathrm{~h}$ at $37^{\circ} \mathrm{C}$. Following this, the medium was discarded and DMSO was added to solubilize the reaction product formazan by shaking for $15 \mathrm{~min}$. Absorbance at $492 \mathrm{~nm}$ was measured with a microplate reader (ELx800, Bio-Tek, USA). Cell viability of vehicle-treated control group was defined as $100 \%$. Cell viability was expressed as a percentage of the value in control cultures.

\subsection{MsrA Homology Modeling}

MODELLER suite (version 9.11, Sali \& Blundell 1993) was used to construct the model of rat MsrA, and the template was a known complex of Met sulfoxide reductase A from Neisseria meningitides (PDB ID $3 \mathrm{BQF})$ as descripted previously ${ }^{[29]}$. Then residue CYS72 of MsrA was modified to its oxide state, just called CYO72 here, and the modified-MsrA was named CYO72-MsrA for convenience. The coarse model of CYO72-MsrA was then refined by a $12 \mathrm{~ns}$ standard molecular dynamics in AMBER 12 (Case $2012 \mathrm{~b}$ ) until the ensemble attained its equilibrium state to get the stable conformation of CYO72-MsrA. During the molecular docking process, the CYO72MsrA was solvated in a truncated octahedron box with $0.1 \mathrm{~mol} / \mathrm{L} \mathrm{NaCl}$ and several another $\mathrm{Na}^{+}$ions added to counter solute charges. L-Met was prepared with academic maestro 9.6 from DESMOND molecular dynamics suite and minimized energetically for further studies. According to the known crystal structure of 
MsrA (PDB ID 3BQF), all of the ligands were docked manually to the active site of CYO72-MsrA to form various complexes, and the $\mathrm{S}-\mathrm{Me}$ group was consistent with that of $3 \mathrm{BQF}$ structure. Again, all of complexes were refined in AMBER 12 with explicit solvent environment and the same ion strength mentioned above. After that, the ligands were pulled 16 angstroms away from the active site to obtain the starting structures for later Steered Molecular Dynamics simulations.

To distinguish the difference of action between ligands and CYO72-MsrA, steered molecular dynamics (SMD) method was conducted for those starting structures prepared above. First, those structures were solvated with similar conditions as described before. One minimization was then done with restraint on solutes following one non-restraint minimization to get rid of steric clashes inside the ensembles. Next, all of those systems were heated within $200 \mathrm{ps}$ from 0 $\mathrm{K}$ to $300 \mathrm{~K}$ with weak restraints on solutes to prevent ligands shifting away from enzyme. After heating those systems completely, NVT simulations were arranged to all systems at $300 \mathrm{~K}$. All of NVT simulations were sustained for a longer period of $10 \mathrm{~ns}$ with time step 2 fs and 5000000 steps alleger. Finally, several one-ns SMD simulations were performed for every ligand, and they pulled the ligands into the active site of CYO72MsrA from 16 angstroms to their own equilibrated states of complexes. In the meantime backward pulling simulations were done to pull ligands away from the active site of CYO72-MsrA. The forward and backward works of pulling $v s$. a series distances could be figured for later analysis. All of MD simulations described here were completed in Amber 12 (Case 2012a) with CYO72MsrA parameterized using the Amber 99SB-ildn force field $^{[39]}$. CYO72, which represents the oxidized form of Met, was parameterized with antechamber of Amber suites by using the GAFF force field and the charges of all non-standard residues including CYO and L-Met were calculated from an ORCA 2.8 quantum chemistry program package from the development team at the University of Bonn. Structure was optimized at the HF/6-31 g (d) level of theory (Neese. 2010). Spinrestricted Kohn-Sham determinants were chosen to describe the closed-shell wave functions, employing the resolution of identity (RI) approximation and the tight self-consistent field (SCF) convergence criteria provided by ORCA. In addition, some calculations were conducted in parallel on GTX 690 GPU or $3.2 \mathrm{G}$ multi-core Xeon $5580 \mathrm{CPU}$ to accelerate the processes of simulations.

\subsection{Statistical Analysis}

Data were expressed as means \pm standard deviation (SD). Comparison between two groups was evaluated by the unpaired Student's $t$-test. Multiple comparisons were tested by one-way analysis of variance (ANOVA) followed by Duncan's multiple-range test. Differences were considered significant at $P<0.05$.

\section{RESULTS}

\subsection{L-Met Reduces Antimycin A-induced Superoxide Generation in PC12 Cells via a MsrA-dependent Mechanism}

We induced $\mathrm{O}_{2} \cdot \cdot$ production in $\mathrm{PC} 12$ cultured cells by a mitochondrial respiratory complex III inhibitor, antimycin A, as previously described ${ }^{[29]}$. Antimycin A increased levels of $\mathrm{O}_{2}-\cdot$, which were judged by the fluorescence signals emitted by the oxidized forms of Mito-SOX (fig. 1). Bath application of antimycin A $(100 \mu \mathrm{g} / \mathrm{mL})$ for $0.5 \mathrm{~h}$ induced an increase of ROS level to $320 \% \pm 42 \%$ of control group $(n=9, P<0.01 v s$. blank control), which could be alleviated by co-incubation
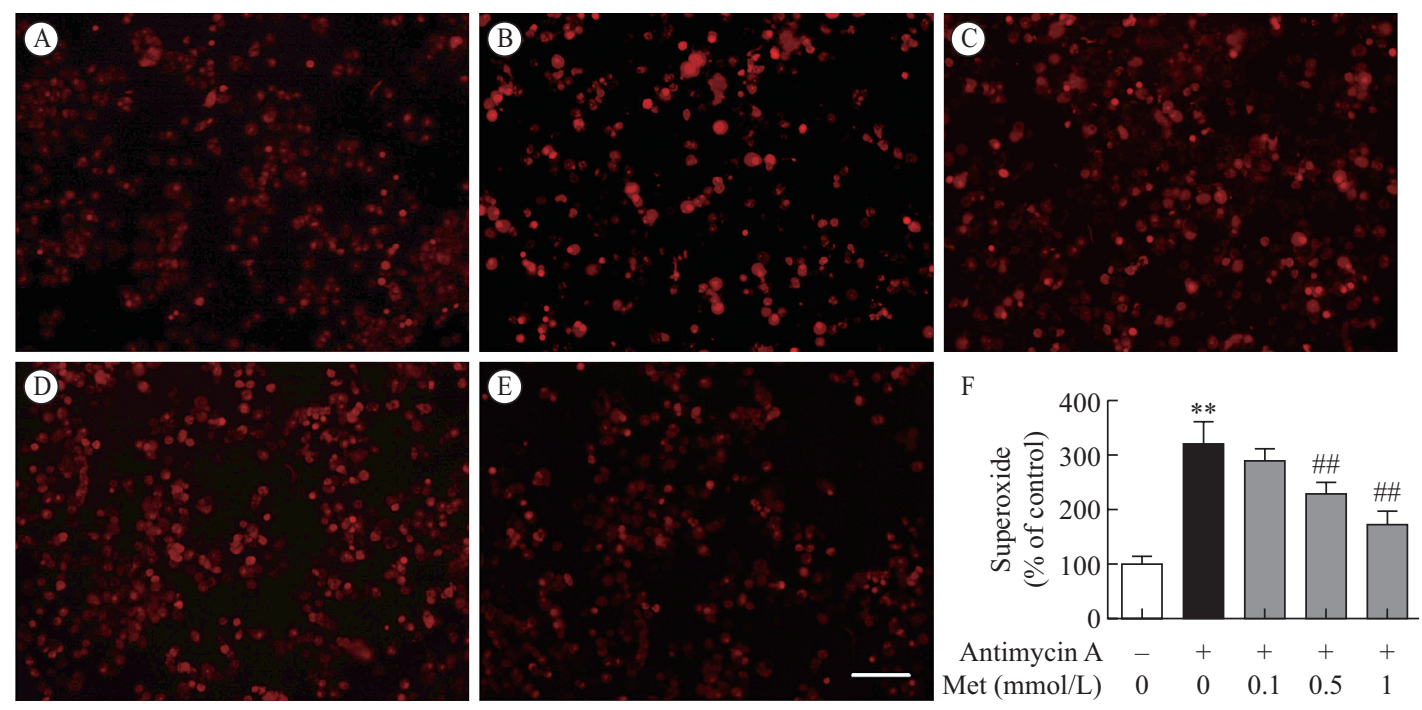

Fig. 1 L-Met reduces antimycin A-induced superoxide generation in PC12 cells.

PC12 cells were pretreated with 0 (A, B), 0.1 (C), 0.5 (D), or $1 \mathrm{mmol} / \mathrm{L} \mathrm{L}-\mathrm{Met}(\mathrm{E})$ for $30 \mathrm{~min}$ and then incubated with vehicle (A) or antimycin A (B-E, $100 \mu \mathrm{g} / \mathrm{mL}$ for $30 \mathrm{~min}$ ). The levels of superoxide were detected with MitoSOX red. Scale bars represent $100 \mu \mathrm{m}$. The fluorescence intensity of superoxide was determined (F). ${ }^{* *} P<0.01 v s$. control group, ${ }^{\# \#} P<0.01 v s$. antimycin A group 
with L-Met. L-Met $(0.1,0.5$ and $1 \mathrm{mmol} / \mathrm{L})$ reduced the superoxide level to $291 \% \pm 21 \%, 230 \% \pm 21 \%$ and $174 \% \pm 22 \%$ of control group, respectively ( $n=6$, $P<0.01$ vs. model, one way ANOVA, fig. 1$)$.

To explore whether MsrA is necessary for antioxidant activity of L-Met, we knocked down the MsrA expression in the PC12 cells. After treatment with lentiviral-expressed specific shRNAs against MsrA, the MsrA expression levels were significantly
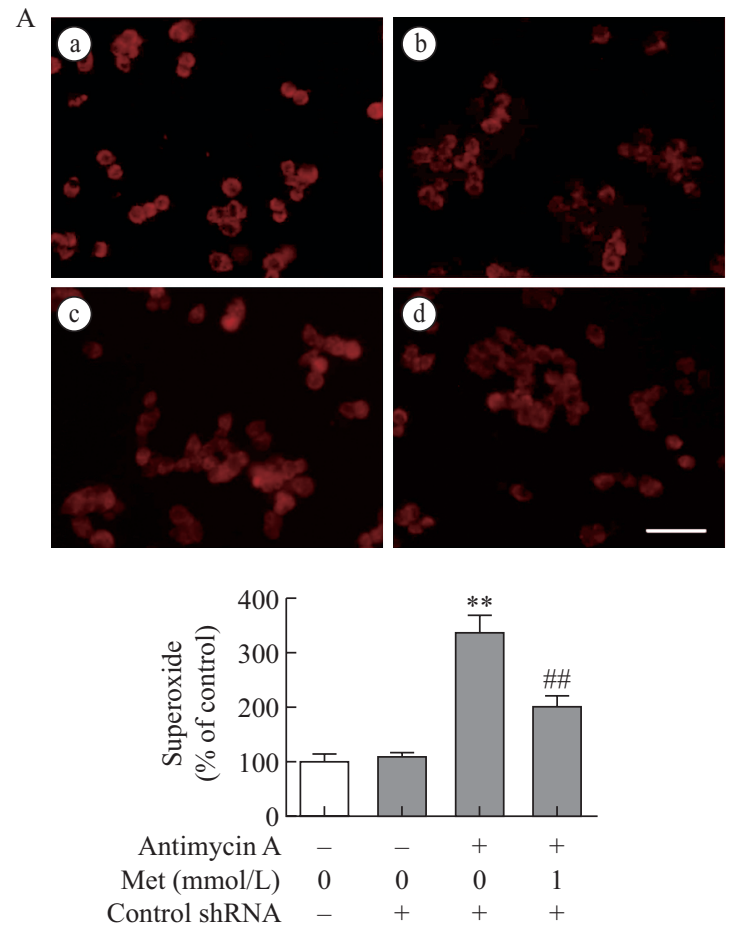

Fig. 2 L-Met reduces antimycin A-induced superoxide generation in PC12 cells via a MsrA-dependent mechanism.

A, B: PC12 cells were transfected with scramble shRNA (A) or MsrA shRNA (B). The transfected cells were pretreated with vehicle $(\mathrm{a}-\mathrm{c})$ or L-Met $(\mathrm{d}, 1 \mathrm{mmol} / \mathrm{L}$ for $30 \mathrm{~min})$ and then incubated with antimycin A (c, d, $100 \mu \mathrm{g} / \mathrm{mL}$ for $30 \mathrm{~min})$. The release of superoxide was determined by the mitoSOX red fluorescence. And the fluorescence intensity of mitoSOX red was calculated in the statistics. Data are expressed as means $\pm \mathrm{SD}(n=6-9),{ }^{* *} P<0.01 v s$. control group, ${ }^{\#} P<0.01 v s$. model group, or $v s$. untreated L-Met with scrambled shRNA group

\subsection{MsrA Enhances the Radical Scavenging Property of Thiomethyl Group on Met via Formatting Sulfo- nium Intermediate}

To confirm the antioxidant activity of L-Met in vitro, we evaluated the ROS-scavenging activity of L-Met by EPR. In EPR assay, hydroxyl radical was induced by Fenton reaction and trapped by DMPO to form a stable spin adduct DMPO-OH. L-Met reduced the signal of spin adduct to $58.8 \% \pm 6.1 \%$ of vehicletreated group at $1 \mathrm{mmol} / \mathrm{L}(P<0.05, n=6-8$, one way ANOVA, fig. 3A-3D). Meanwhile, $0.1 \mathrm{mmol} / \mathrm{L}$ L-Met could not reduce the spin adduct signal $(94.1 \% \pm 11.6 \%$ of vehicle, $n=6, P>0.05$ ).

To validate this hypothesis, we observed the effect of MsrA on the reaction between ROS and L-Met in vitro using a recombinant rat MsrA (rMsrA). In our previous study, we found that neither MsrA nor nonactive MsrA alone has perceptible effects on EPR decreased. The effect of L-Met $(1 \mathrm{mmol} / \mathrm{L})$ on antimycin A-induced superoxide increase in the PC12 cells was abolished, suggesting that MsrA is essential for the anti-oxidant activity of L-Met in cells (fig. 2A and $2 \mathrm{~B} ; 201 \% \pm 19 \%$ of control group in L-Met with scrambled shRNA group vs. $337 \% \pm 32 \%$ in vehicle with scrambled shRNA group; $357 \% \pm 34 \%$ in L-Met with MsrA shRNA group vs. $325 \% \pm 41 \%$ in vehicle with MsrA shRNA group).
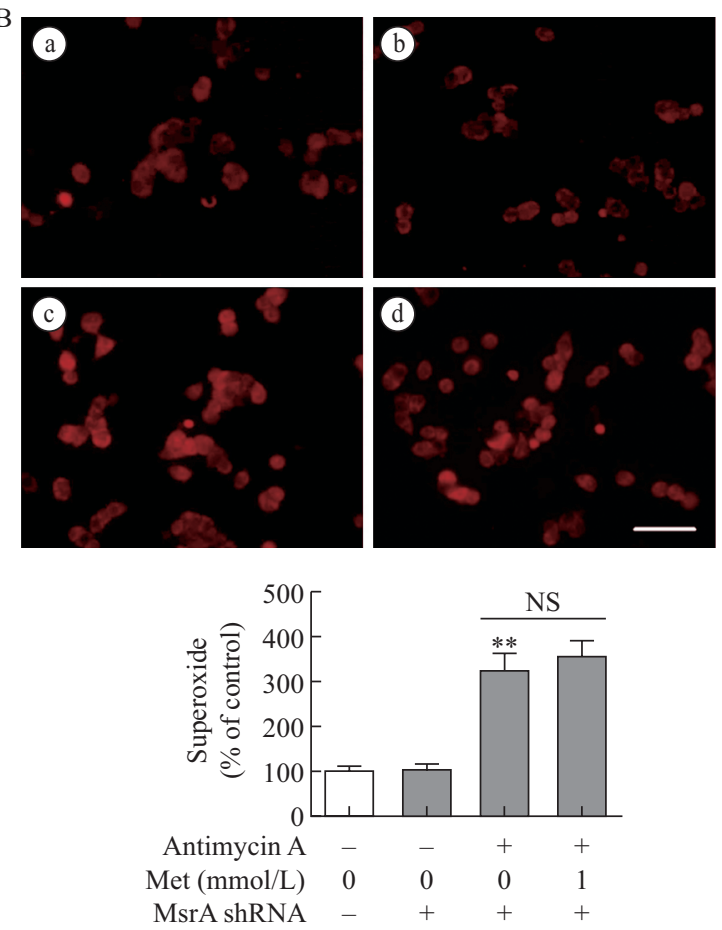

signals. EPR assay (fig. 2E-2G) showed that cotreatment of L-Met with non-active MsrA or active MsrA decreased the DMPO-OH signal amplitude to $88.6 \% \pm 11.0 \%(P<0.05$, Student's $t$ test, $n=6-8)$ or $59.9 \% \pm 2.6 \%(P<0.05$, Student's $t$ test, $n=6-8)$ of vehicle group in the presence of $0.1 \mathrm{mmol} / \mathrm{L} \mathrm{L}-\mathrm{Met}$, respectively. Compared to non-active MsrA group, active MsrA group significantly decreased the DMPOOH signal ( $P<0.01, n=6-8$, Student's $t$ test), indicating that MsrA facilitates the reaction of L-Met and ROS.

Then, to understand how MsrA catalyzes the oxidation of L-Met, homology modeling was used to visualize structural interactions between Met and MsrA. First, we observed that L-Met could bind to the catalytic pocket of MsrA (fig. $2 \mathrm{H}$ ). The space of the pocket was formed by the side chains of Cys72, Phe73, Trp74, Tyr103 and Glu115. Previous studies had shown that the first step of MsrA-catalytic oxidation is to form 


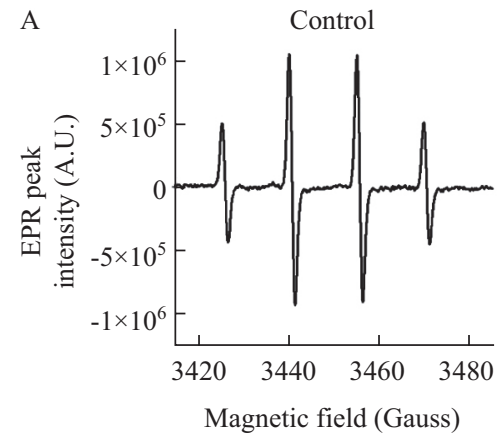

D

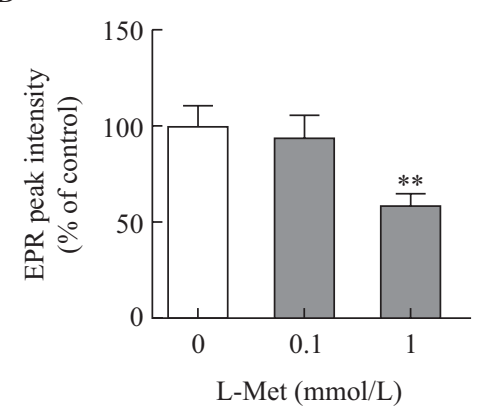

G

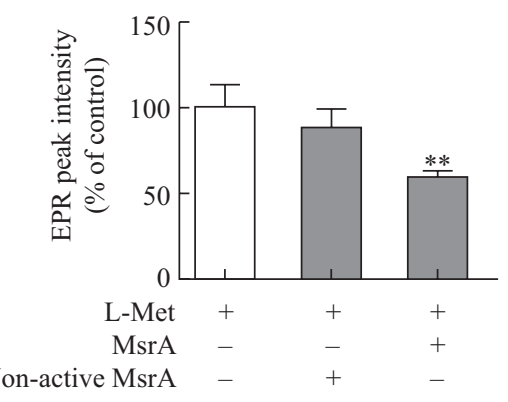

B

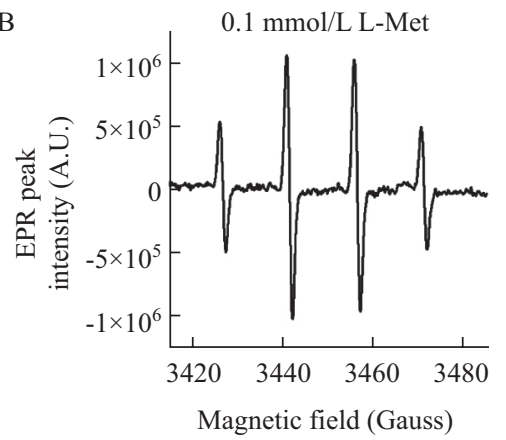

E

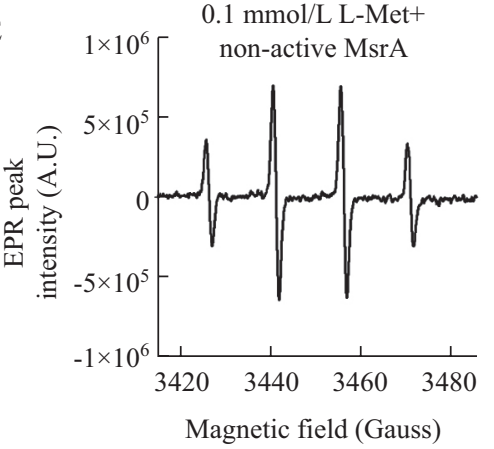

$\mathrm{H}$

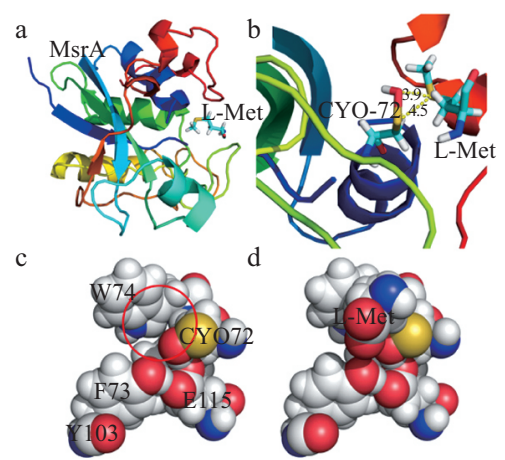

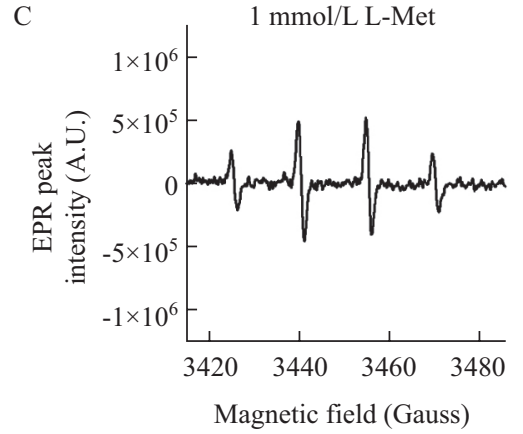

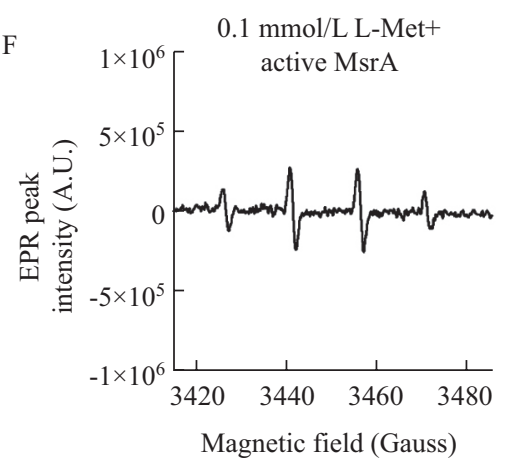

Fig. 3 MsrA enhances the radical scavenging property of thiomethyl group on Met via formatting sulfonium intermediate.

A-C: EPR spectra of DMPO-OH spin adduct during the reaction of $0.25 \mathrm{mmol} / \mathrm{L} \mathrm{H} \mathrm{O}_{2}$ with $0,0.1$, or $1 \mathrm{mmol} / \mathrm{L} \mathrm{L-Met}$. L-Met $(1 \mathrm{mmol} / \mathrm{L})$ decreased the ROS signal. D: The levels of EPR peak intensity were obtained after treatment with L-Met $(n=6-8)$, and the untreated control was set as $100 \%$. E, F: Active or non-active MsrA enzyme was added into $0.1 \mathrm{mmol} / \mathrm{L}$ L-Met reaction tube. The ROS signal of active MsrA group was reduced significantly. G: The levels of EPR peak intensity were measured after treatment with L-Met and MsrA or non-active MsrA ( $n=6-8)$, and the non-enzyme control was set as $100 \%$. H-a: Structural interactions were visualized between L-Met and MsrA. Catalytic site of MsrA consisted with CYO72, F73, W74, Y103 and E115. H-b: L-Met binding to CYO72 site of MsrA with highlighted dash line to indicate the distances. The unit is Angstrom. $\mathrm{Hc}, \mathrm{Hd}$ : Molecular docking suggests MsrA has a binding site for L-Met. Data are expressed as means $\pm \operatorname{SD}(n=6-8),{ }^{* *} P<0.01 v s$. vehicle-treated control group

a sulfenic acid residue on Cys 72 by $\operatorname{ROS}^{[29]}$. Thus, to induce the sulfoxide structure, the reaction between oxygen atom on the Cys72 (CYO72-S/-O) and S atom from substrates is the limited step. To increase the reaction rate, a preferred orientation in the pocket is required for the substrate. Thus, we analyzed the orientation of different MsrA substrates in the active site of MsrA and found that L-Met adopted a preferred orientation than most of the others with the distance of O-S $3.9 \AA$. We found that residues Tyr103, Glu115, Tyr155, Phe73 and Trp74 contributed to the oxidation of L-Met, especially Trp74, Tyr103 and Glu115. When L-Met bound, the distances of donor and acceptor atoms (D-H...A) between the $\mathrm{O}$ atom from $\mathrm{CYO} 72$ and the $\mathrm{H}$ atom from Tyr103-OH and Glu115-COOH were $3.0 \AA$ and $2.7 \AA$, respectively. The two hydrogen bonds helped the transfer of $\mathrm{O}$ atom from $\mathrm{CYO} 72$ to the $\mathrm{S}$ atom from sulfide and facilitated the oxidation of L-Met.

2.3 SMLC, an L-Met Analogue and ROS Scavenger,
Emerges as a Substrate of MsrA-catalytic Met
Oxidase Activity
To confirm the antioxidant activity of SMLC, a hydrophilic cysteine-containing compound naturally found in garlic and onion (fig. 4A), we evaluated the ROS-scavenging activity of SMLC by EPR. In the 
same experiment settings of L-Met, SMLC reduced the signal of spin adduct to $26.9 \% \pm 6.7 \%$ of vehicle-treated group at $10 \mathrm{mmol} / \mathrm{L}(P<0.01, n=5$, one way ANOVA, fig. 4B-4F). Meanwhile, 0.1 or $1 \mathrm{mmol} / \mathrm{L}$ SMLC could not reduce the spin adduct signal $(98.9 \% \pm 7.4 \%$ and $94.8 \% \pm 10.7 \%$ of vehicle group, $P>0.05$ ).

Then we observed the effect of MsrA on the reaction between ROS and SMLC. The EPR assay showed cotreatment of $0.1 \mathrm{mmol} / \mathrm{L}$ SMLC and non-active MsrA (boiled) or active MsrA decreased the DMPO-OH signal amplitude to $64.61 \% \pm 1.8 \%(P<0.05, n=5-7$, Student's $t$ test, fig. 4G-4J) or $17.5 \% \pm 1.7 \%(P<0.01$, $n=7-8$, Student's $t$ test) of vehicle group in the presence of $0.1 \mathrm{mmol} / \mathrm{L}$ SMLC, respectively. Compared to nonactive MsrA group, active MsrA with SMLC exerted a much better anti-oxidant activity in the Fenton system $(P<0.01, n=5-8$, Student's $t$ test), which indicated that MsrA significantly facilitates the reaction of SMLC and ROS.

\subsection{SMLC Reduces Antimycin A-induced Mitoch- ondrial Membrane Depolarization in PC12 Cells}

As mitochondria are critical for apoptosis, it was logical to explore the effect of Met or SMLC on mitochondrial function. In this study, we used JC-1 as a
A<smiles>CSCC[C@H](N)C(=O)O</smiles><smiles>CSC[C@H](N)C(=O)O</smiles>

S-Methyl-L-Cysteine (SMLC)

$\mathrm{D}$

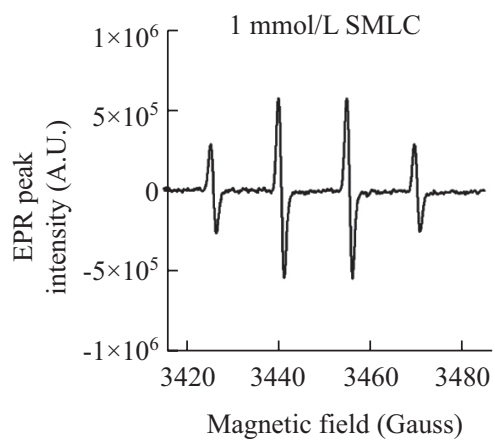

G

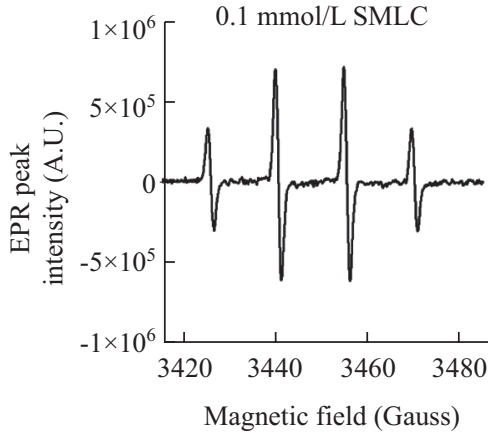

J

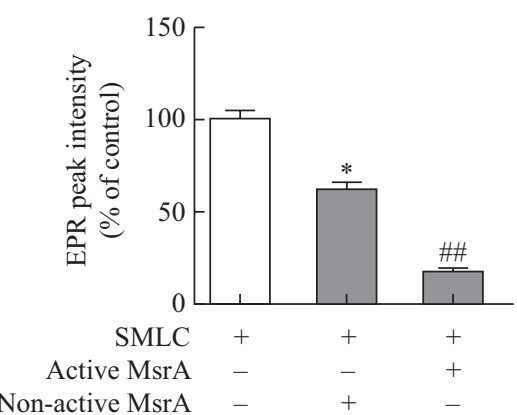

B

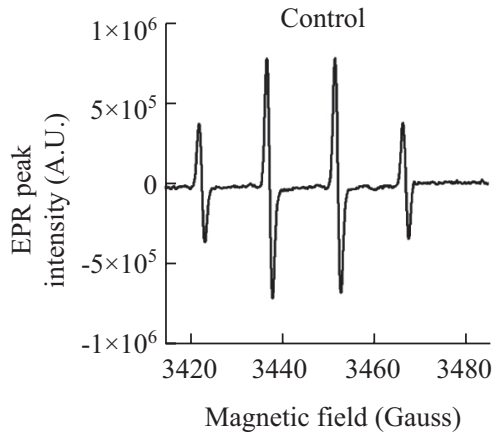

E
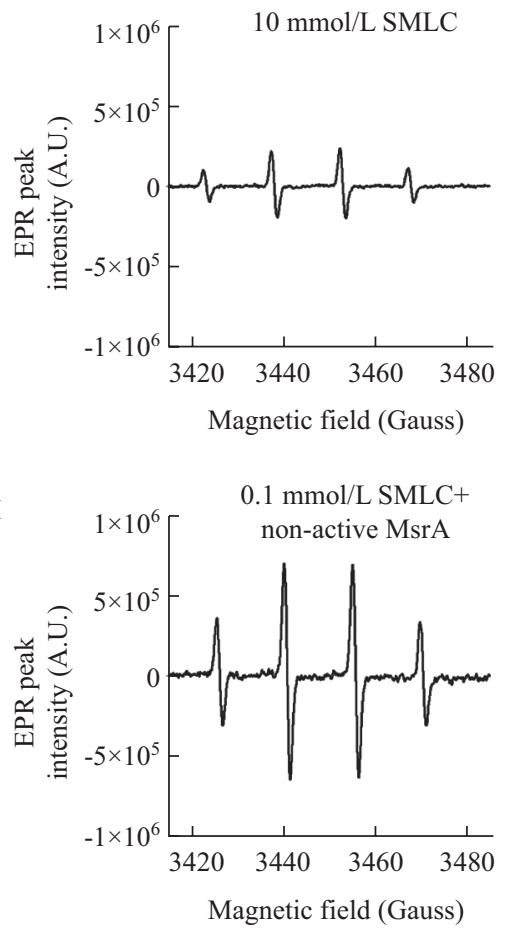
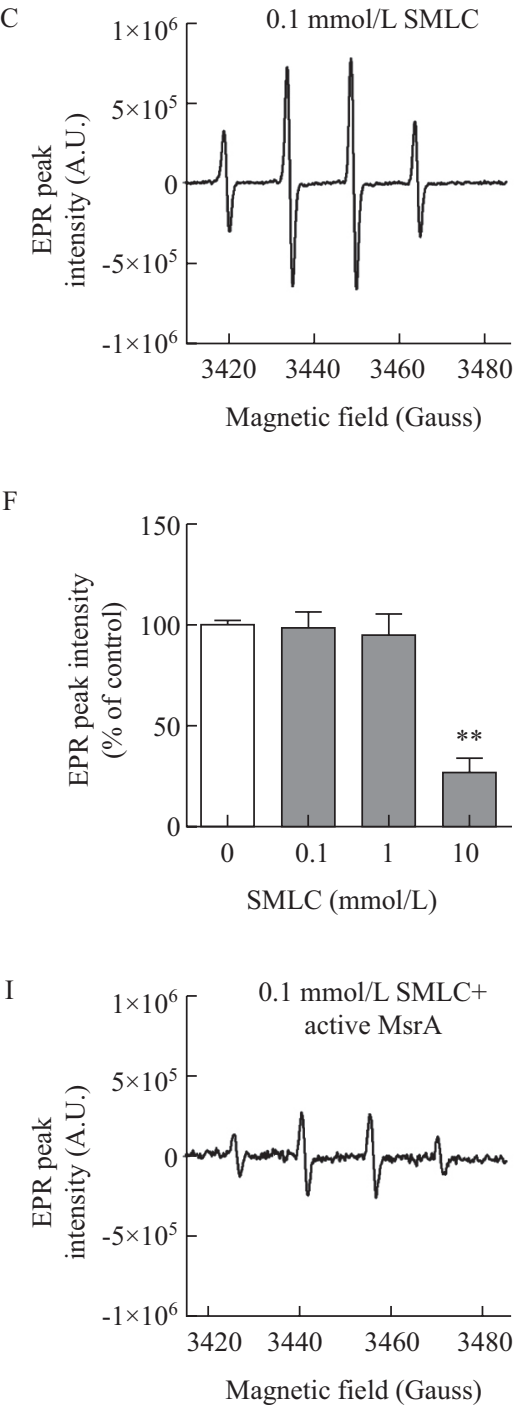

Fig. 4 MsrA enhances the ROS scavenging property of SMLC.

A: The chemical structure of L-Met and SMLC. B-E: EPR spectra of DMPO$\mathrm{OH}$ spin adduct during the reaction of $0.25 \mathrm{mmol} / \mathrm{L} \mathrm{H}_{2} \mathrm{O}_{2}$ with $0,0.1,1$ or 10 $\mathrm{mmol} / \mathrm{L}$ SMLC. SMLC decreased the ROS signal at $10 \mathrm{mmol} / \mathrm{L}$. F: The levels of EPR peak intensity were included in the statistics $(n=5-6)$, and the untreated control was set as $100 \%$. G-I: Active or non-active MsrA enzyme was added into $0.1 \mathrm{mmol} / \mathrm{L}$ SMLC reaction tube. The ROS signal of active MsrA group was reduced significantly. J: The levels of EPR peak intensity were included in the statistics $(n=6-8)$, and the non-enzyme control was set as $100 \%$. Data are expressed as means \pm SD $(n=5-8) .{ }^{*} P<0.05,{ }^{* *} P<0.01 v s$. vehicle-treated control group; ${ }^{\#} P<0.01$ vs. non-active MsrA group 
fluorescent probe to detect the change in mitochondrial membrane potential by the change in fluorescence color. Compared with control group, treatment with $100 \mathrm{ng} / \mathrm{mL}$ antimycin A for $30 \mathrm{~min}$ led to mitochondrial membrane potential collapse as shown by enhanced $\mathrm{red} /$ green ratio. Then cells were pretreated with 1 $\mathrm{mmol} / \mathrm{L} \mathrm{SMLC}$ or $1 \mathrm{mmol} / \mathrm{L} \mathrm{L}-$ Met at $0.5 \mathrm{~h}$ before adding antimycin $\mathrm{A}$ until the end. The red/green ratio was increased by SMLC or L-Met treatment (SMLC: $31.3 \% \pm 4.1 \%$, L-Met: $31.7 \% \pm 4.8 \%, n=8, P<0.01$, fig. 5) compared with antimycin A-treated vehicle group ( $22.4 \% \pm 1.0 \%$ of control, $n=5, P<0.01 v s$. control).

\subsection{SMLC Protects SH-SY5Y Cells against MPP ${ }_{-}^{+}$ induced Cytotoxicity}

Then, we examined whether the radical-scavenging effect of L-Met and SMLC conferred neuroprotection. We used a $\mathrm{MPP}^{+}$-induced neurotoxocity model. SHSY5Y cells were treated with $2 \mathrm{mmol} / \mathrm{L} \mathrm{MPP}^{+}$for 8,16 , 24 and $48 \mathrm{~h}$. MTT assay showed that $\mathrm{MPP}^{+}$reduced the cell viability in a time-dependent manner (fig. 6A). The cell viability decreased to $81.2 \% \pm 6.4 \%, 55.9 \% \pm 12.4 \%$
B
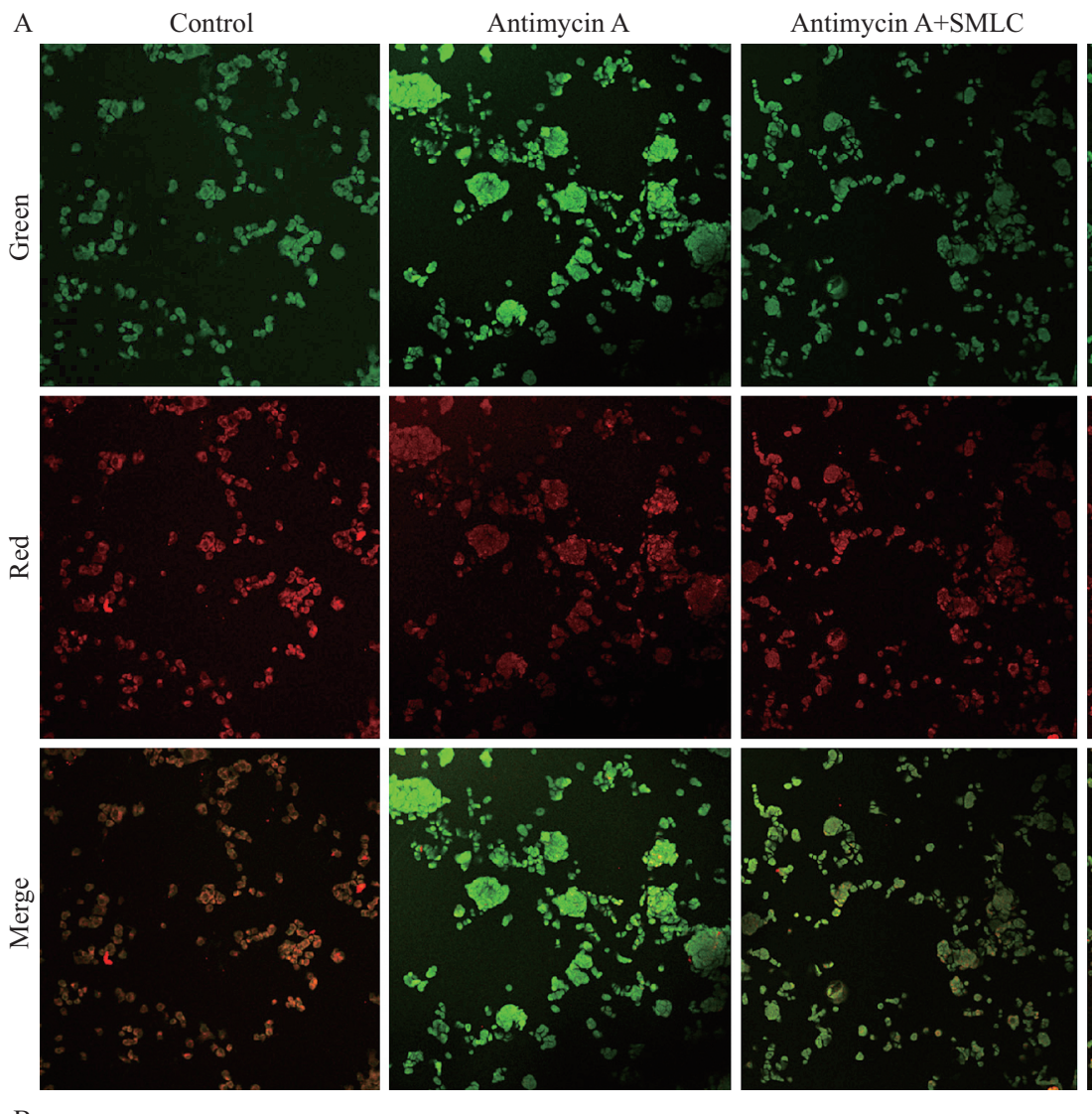

and $25.2 \% \pm 4.7 \%$ of control group in $8,16,24$ and 48 h-treated groups. Then cells were pretreated with various concentrations of L-Met at $0.5 \mathrm{~h}$ before adding $\mathrm{MPP}^{+}$until the end. The cell viability was increased by L-Met treatment $(0.1 \mathrm{mmol} / \mathrm{L}: 31.3 \% \pm 4.1 \%, 0.5$ $\mathrm{mmol} / \mathrm{L}: 31.7 \% \pm 4.8 \%$ and $1 \mathrm{mmol} / \mathrm{L}: 40.2 \% \pm 5.6 \%$, $n=8, P<0.01$, fig. $6 \mathrm{~B}$ ) compared with $\mathrm{MPP}^{+}$-treated vehicle group $(22.4 \% \pm 1.0 \%$ of control, $n=8, P<0.01 v s$. control). SH-SY5Y cells were pretreated with L-Met for $0.5 \mathrm{~h}$ before adding $\mathrm{MPP}^{+}$. Then we tested whether SMLC could alleviate $\mathrm{MPP}^{+}$-induced neurotoxicity. Compared with $\mathrm{MPP}^{+}$-treated group $(22.5 \% \pm 5.3 \%$ of control, $P<0.01)$, the cell viability was increased by SMLC treatment $(0.1 \mathrm{mmol} / \mathrm{L}: 34.6 \% \pm 4.5 \%, 0.5$ $\mathrm{mmol} / \mathrm{L}: 41.1 \% \pm 2.7 \%$ and $1 \mathrm{mmol} / \mathrm{L}: 45.5 \% \pm 2.5 \%$, $n=8, P<0.01$, fig. $6 \mathrm{C}$ ), when the cells were pretreated with various concentrations of SMLC for $0.5 \mathrm{~h}$ before adding $\mathrm{MPP}^{+}$until the end. These data indicated a protective role of MsrA-catalytic Met oxidase activity initiated by L-Met and SMLC in $\mathrm{MPP}^{+}$-induced neurotoxicity.
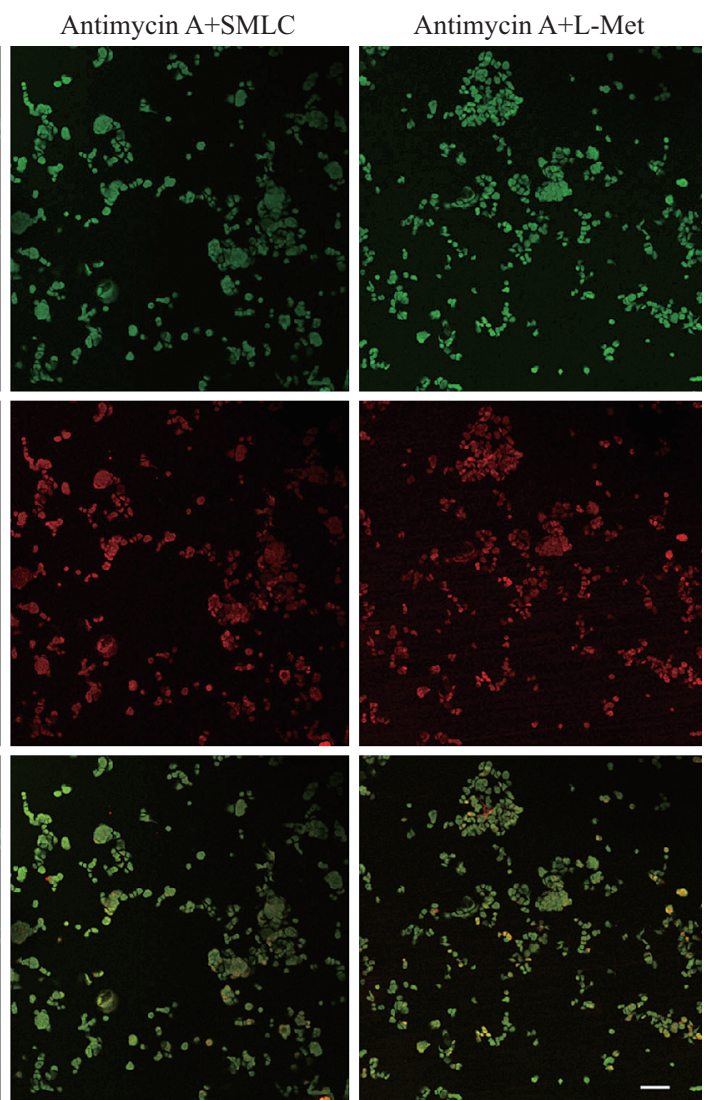

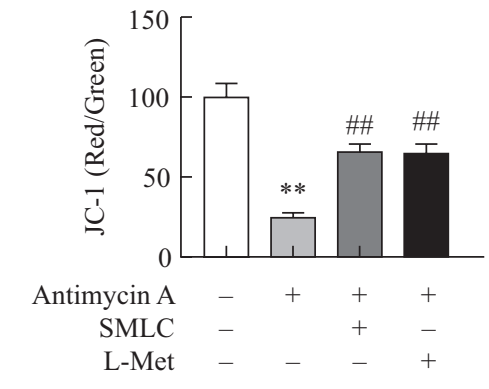

Fig. 5 SMLC reduced antimycin-induced mitochondrial membrane depolarization in PC12 cells.

A, B: PC12 cells were pretreated with $1 \mathrm{mmol} / \mathrm{L}$ SMLC or 1 $\mathrm{mmol} / \mathrm{L} \mathrm{L}-\mathrm{Met}$ for $30 \mathrm{~min}$ and then incubated with antimycin A $(100 \mu \mathrm{g} / \mathrm{mL}$ for $30 \mathrm{~min})$. The mitochondrial membrane potential (JC-1 staining, red/green fluorescence ratio) was photographed and quantified by fluorescence microscopy. Data are expressed as means \pm SD. $n=5,{ }^{* *} P<0.01 v s$. control group, ${ }^{\#} P<0.01$ vs. model group 


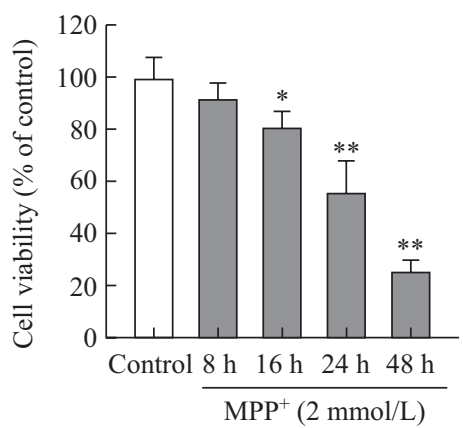

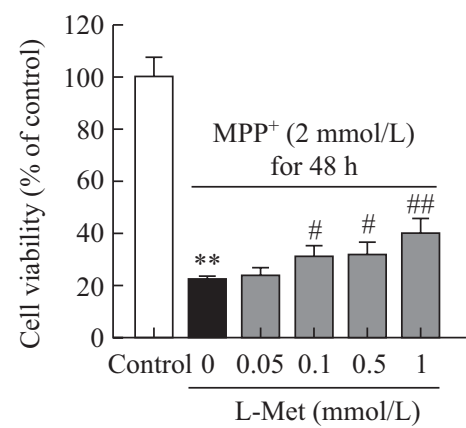

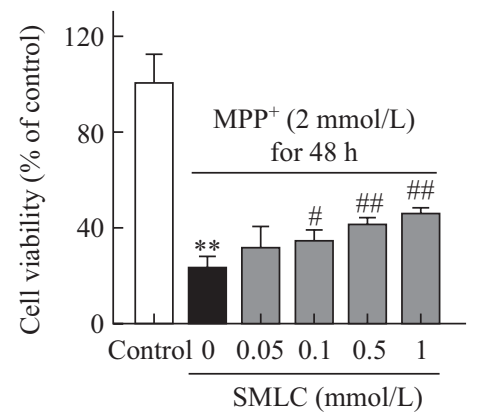

D<smiles>[13CH3]C(=O)O</smiles>

$[\mathrm{O}]$<smiles>CC(=O)O</smiles><smiles>O[As]</smiles>

Cys $72-\mathrm{S}-\mathrm{H}$<smiles>C[C@H]1CCCC[C@H]1CS(C)=O</smiles>
Cys $72-\mathrm{S}-\mathrm{OH}$<smiles>CSC[C@H](N)C(=O)O</smiles><smiles>CC(=O)O</smiles><smiles>O=CO[Hg]PO[Na]</smiles><smiles>CS(=O)CC[C@H](N)C(=O)O</smiles><smiles>CC(=O)O</smiles><smiles>C1CC[Te]C1</smiles><smiles>CS1(CC[C@H](N)C(=O)O)O[Tl]O1</smiles>

Fig. 6 Protective effect of L-Met and SMLC against MPP ${ }^{+}$-induced cytotoxicity in SH-SY5Y cells

A: effects of $\mathrm{MPP}^{+}$treatment time on the cell viability of SH-SY5Y cells. SH-SY5Y cells were incubated with $2 \mathrm{mmol} / \mathrm{L} \mathrm{MPP}$ for 8, 16, 24 or $48 \mathrm{~h}$, and the cell viability was assayed using MTT. B: the effect of L-Met on MPP'-induced cytotoxicity in SH-SY5Y cells. Cells were pretreated with various concentrations of L-Met for $0.5 \mathrm{~h}$, and $\mathrm{MPP}^{+}(2 \mathrm{mmol} / \mathrm{L})$ was added for an additional $48 \mathrm{~h}$. C: The cell viability rates showed the effect of 0.05 to $1 \mathrm{mmol} / \mathrm{L}$ SMLC on MPP ${ }^{+}$-induced cytotoxicity in SHSY5Y cells. D: proposed mechanism of SMLC oxidation catalyzed by MsrA. Data are expressed as means \pm SD. $n=8,{ }^{* *} P<0.01$ vs. control group; ${ }^{\#} P<0.05,{ }^{\#} P<0.01$ vs. $\mathrm{MPP}^{+}$-treated group

\section{DISCUSSION}

Our study provided evidence that MsrA helped L-Met and its analogue SMLC scavenge radicals via formatting sulfonium intermediate, which protected cells from oxidative stress and neutron toxin-induced neurotoxicity. With release of SMLC sulfoxide, the reduced form of MsrA is formed. After MsrA knockdown, the anti-oxidant activity of L-Met in PC12 cells was nearly abolished. Meanwhile, computational chemistry evidence showed that Met-like structure was a substrate of oxide-MsrA. We believe that the oxygen atom on the sulfenic acid was derived from ROS or radicals. A lone pair of electrons on the Met or SMLC sulfur attacked the sulfonicsulfur to form the positively charged sulfonium intermediate. Glu115 and Tyr103 acted as a proton donor and were stabilized by hydrogen bonding with SMLC (fig. 6D). These data highlight the role of MsrA in the detoxication of mitochondrial ROS-generating toxins.

Epidemiologically, environmental neurotoxins, such as pesticides, $\mathrm{MPP}^{+}$, 6-hydroxydopamine, rotenone, 3-nitropropionic acid and paraquat, induced neurotoxicity via triggering mitochondrial oxidative stress burdens ${ }^{[1-5]}$. Levels of ROS exceed the antioxidant capacity of the mitochondria of neurons. These neurotoxins are promising candidates for causative factors of neurodegenerative diseases, including PD. Aging-associated decline in the endogenous antioxidant defense increased the susceptibility to neurotoxins. Among the endogenous antioxidant defenses, MCRC, which depends on the anti-oxidation activity of proteinbound Met residues and their redox cycle containing Met-MetO-Met, plays a critical role in the protection 
of key proteins. In the MCRC, Met residues in proteins act as a "sink" for many reactive species, and Msrs catalyze a thioredoxin-dependent reduction of MetO back to Met. This cyclic interconversion of protein Met residues between oxidized and reduced forms may be considered an efficient ROS-scavenging mechanism in vivo. Although most studies have indicated a role of MCRC in the aging-related diseases ${ }^{[40,41]}$, much less is known about its role in the neuro-toxicology of ROSgenerating toxins. Our previous studies revealed that Met alleviates $\mathrm{H}_{2} \mathrm{O}_{2}$-induced mitochondrial injury and 12-O-tetradecanoyl-phorbol-13-acetate (TPA)-induced skin oxidation ${ }^{[42]}$. Selective dopaminergic neuronal cell death caused by environmental neurotoxin $\mathrm{MPP}^{+}$has been widely used as a cell model of PD. In the current study, we further observed that Met also alleviates $\mathrm{MPP}^{+}$-induced neurotoxicity of SH-SY5Y cells. All the data raised the critical role of MCRC in the detoxication of mitochondrial ROS-generating toxins.

It is conventionally believed that the mitochondrial ROS scavenging effect of MCRC is mainly due to the natural anti-oxidation activity of Met residues. Under oxidative stress, MsrA can maintain an effective concentration of Met by reducing MetO timely via activating its reductase. Our previous study found that under oxidative stress, more than $80 \%$ of protein-bound Met residues are kept in a reduced form ${ }^{[43]}$, indicating that there is a sufficient store of Met. Although L-Met can act as an effective $\mathrm{H}_{2} \mathrm{O}_{2}$ scavenger in vitro in the presence of a high concentration of $\mathrm{H}_{2} \mathrm{O}_{2}$ (above 1 $\mathrm{mmol} / \mathrm{L}$ ), after inhibition of MsrA function by DMSO, the antioxidation of Met $(1-5 \mathrm{mmol} / \mathrm{L})$ on $\mathrm{CHO}$ cells is largely abolished ${ }^{[42]}$. Recently, it has been demonstrated that MsrA also serves as a stereospecific methionine oxidase $^{[43]}$, which may facilitate the reaction of Met with ROS. Here, we observed that knockdown of MsrA by shRNA nearly abolished the antioxidation of Met in the mitochondrial ROS generation. In Fenton system, EPR spin-trapping assay revealed that MsrA facilitated the Met $(1 \mathrm{mmol} / \mathrm{L})$-mediated scavenging effect on hydroxyl radicals. Thus, Met is not merely an antioxidant, and its action may require a participation of MsrA in vivo.

MsrA has historically been considered a reductase to repair damaged proteins, not an ROS scavenger ${ }^{[44,45]}$. In spite of its impressive protective effects in neurotoxity ${ }^{[46,47]}$, the precise mechanisms and fundamental chemical principles for MsrA-mediated mitochondrial ROS elimination remain largely unclear. Although MsrA may exhibit antioxidation via maintaining an effective concentration of Met by reducing MetO timely, this study, together with our previous work, has demonstrated that the stereospecific Met oxidase activity may play a vital role in the anti-oxidation of MsrA, which may afford the antioxidant effect against neurotoxins, including $\mathrm{H}_{2} \mathrm{O}_{2}$, antimycin and MPP .
By computation, we found that the lone pair electrons on the methylthiol-sulfur nucleophilicly of sulfide attacked the sulfenic sulfur in active site of MsrA to form the positively charged sulfonium intermediate. Then, MsrA catalyzed the transition and released the sulfoxide. When ROS bursted in vivo, ROS induced a sulfenic acid residue on Cys 72 of MsrA, which was followed by the reaction between oxygen atom on CYO72 and S atom of DMS. The Phe73 and Trp74 in MsrA facilitated Met to bind the active center via hydrophobic bond, and Tyr103 and Glu115 increased the oxygen atom transfer from the CYO72 to the $\mathrm{S}$ atom of Met via the hydrogen bond. The peroxidase activity of MsrA significantly facilitated the reactivity of Met and SMLC at a relatively low concentration. The mechanisms of Met and SMLC-mediated radicalscavenging capacity were illustrated in fig. 6D.

Pharmacological enhancement of MsrA function seems to be reasonable therapeutic strategy against aging in clinical practice. Only very few approaches are available to enhance MsrA function ${ }^{[29,37,48,49]}$. Comparing to the reducing activity of MsrA for repairing oxidized proteins, activation of Met oxidase activity of MsrA required a relatively high substrate concentration. To increase the concentrations of substrate, Met supplement may not be an appropriate approach, especially in aging-related diseases, like $\mathrm{PD}$ and $\mathrm{AD}$, for Met is rapidly incorporated into proteins and it increases cardiovascular risk ${ }^{[30,31]}$. In fact, dietary Met restriction, not supplementation, induces beneficial effects ${ }^{[0]}$. For the doubtful problem for Met supplementation, other Met analogs could be considered. SMLC is a safe sulfur containing amino acid naturally found in garlic and onion $^{[33-35]}$, and has been reported to have anti-lipidemic activity and anti-PD effects in Drosophila ${ }^{[36,51]}$. We found that SMLC exerted a better natural anti-oxidant activity and its anti-oxidation was also facilitated by MsrA. SMLC works as a substrate in the Met oxidase activity of MsrA. Moreover, it exerted a good neuroprotection in $\mathrm{MPP}^{+}$-induced injury in SH-SY5Y cells. However, more in vivo evidence to support this view is still required. Whether dietary supplementation with SMLC or L-Met in humans is applicable remains to be tested.

In summary, our data supported that the Met oxidase activity of MsrA might be targeted therapeutically to prevent mitochondrial ROS-generating toxins and aging-associated neurodegenerative diseases by activators like SMLC in the future.

\section{Open Access}

This article is licensed under a Creative Commons Attribution 4.0 International License https://creativecommons.org/licenses/by/4.0/), which permits use, sharing, adaptation, distribution and reproduction in any medium or format, as long as you give appropriate credit to the original author(s) and the source, provide a link to the Creative Commons licence, and indicate if changes were made. 
The images or other third party material in this article are included in the article's Creative Commons licence, unless indicated otherwise in a credit line to the material. If material is not included in the article's Creative Commons licence and your intended use is not permitted by statutory regulation or exceeds the permitted use, you will need to obtain permission directly from the copyright holder. To view a copy of this licence, visit http://creativecommons.org/licenses/by/4.0/.

\section{Conflict of Interest Statement}

The authors declare that there is no conflict of interest with any financial organization or corporation or individual that can inappropriately influence this work.

\section{REFERENCES}

1 Chan MC, Bautista E, Alvarado-Cruz I, et al. Inorganic mercury prevents the differentiation of SH-SY5Y cells: Amyloid precursor protein, microtubule associated proteins and ROS as potential targets. J Trace Elem Med Bio, 2017,41:119-128

2 Cabezas R, Vega-Vela NE, Gonzalez-Sanmiguel J, et al. PDGF-BB Preserves Mitochondrial Morphology, Attenuates ROS Production, and Upregulates Neuroglobin in an Astrocytic Model Under Rotenone Insult. Mol Neurobiol, 2018,55(4):3085-3095

3 Gao C, Chang P, Yang L, et al. Neuroprotective effects of hydrogen sulfide on sodium azide-induced oxidative stress in PC12 cells. Int J Mol Med, 2018,41(1):242-250

4 Kaneko YS, Ota A, Nakashima A, et al. Regulation of oxidative stress in long-lived lipopolysaccharideactivated microglia. Clin Exp Pharmacol Physiol, 2012, 39(7):599-607

5 Wu DC, Teismann P, Tieu K, et al. NADPH oxidase mediates oxidative stress in the 1-methyl-4-phenyl1,2,3,6-tetrahydropyridine model of Parkinson's disease. Proc Natl Acad Sci U S A, 2003,100(10):6145-6150

6 Oyewole AO, Birch-Machin MA. Mitochondriatargeted antioxidants. FASEB J, 2015,29(12):4766-4771

7 Feniouk BA, Skulachev VP. Cellular and Molecular Mechanisms of Action of Mitochondria-Targeted Antioxidants. Curr Aging Sci, 2017,10(1):41-48

8 Genet N, Billaud M, Rossignol R, et al. Signaling Pathways Linked to Serotonin-Induced Superoxide Anion Production: A Physiological Role for Mitochondria in Pulmonary Arteries. Front Physiol, 2017,8:76

9 Wu ZF, Zhang J, Zhao BL. Superoxide Anion Regulates the Mitochondrial Free $\mathrm{Ca} 2+$ through Uncoupling Proteins. Antioxid Redox Sign, 2009,11(8):1805-1818

10 Li Z, Ji GC, Neugebauer V. Mitochondrial Reactive Oxygen Species Are Activated by mGluR5 through IP3 and Activate ERK and PKA to Increase Excitability of Amygdala Neurons and Pain Behavior. J Neurosci, 2011,31(3):1114-1127

11 Liu M, Liu H, Dudley SC. Reactive Oxygen Species Originating From Mitochondria Regulate the Cardiac Sodium Channel. Circ Res, 2010,107(8):967-974

12 Hou Y, Ouyang X, Wan R, etal. Mitochondrial superoxide production negatively regulates neural progenitor proliferation and cerebral cortical development. Stem Cells, 2012,30(11):2535-2547

13 Mailloux RJ. Mitochondrial Antioxidants and the
Maintenance of Cellular Hydrogen Peroxide Levels. Oxid Med Cell Longev, 2018,2018:7857251

14 Stadtman ER, Moskovitz J, Berlett BS, et al. Cyclic oxidation and reduction of protein methionine residues is an important antioxidant mechanism. Mol Cell Biochem, 2002,234(1):3-9

15 Davies MJ. The oxidative environment and protein damage. Biochim Biophys Acta, 2005,1703(2):93-109

16 Luo S, Levine RL. Methionine in proteins defends against oxidative stress. FASEB J, 2009,23(2):464-472

17 Wood JM, Decker H, Hartmann H, et al. Senile hair graying: $\mathrm{H}_{2} \mathrm{O}_{2}$-mediated oxidative stress affects human hair color by blunting methionine sulfoxide repair. FASEB J, 2009,23(7):2065-2075

18 Hansel A, Kuschel L, Hehl S, et al. Mitochondrial targeting of the human peptide methionine sulfoxide reductase (MSRA), an enzyme involved in the repair of oxidized proteins. FASEB J, 2002,16(8):911-913

19 Vougier S, Mary J, Friguet B. Subcellular localization of methionine sulphoxide reductase A (MsrA): evidence for mitochondrial and cytosolic isoforms in rat liver cells. Biochem J, 2003,373:531-537

20 Brennan LA, Kantorow M. Mitochondrial function and redox control in the aging eye: role of MsrA and other repair systems in cataract and macular degenerations. Exp Eye Res, 2009,88(2):195-203

21 Picot CR, Petropoulos I, Perichon M, et al. Overexpression of MsrA protects WI-38 SV40 human fibroblasts against $\mathrm{H} 2 \mathrm{O} 2$-mediated oxidative stress. Free Radic Biol Med, 2005,39(10):1332-1341

22 Liu F, Hindupur J, Nguyen JL, et al. Methionine sulfoxide reductase A protects dopaminergic cells from Parkinson's disease-related insults. Free Radical Bio Med, 2008,45(3):242-255

23 Cabreiro F, Picot CR, Perichon M, et al. Overexpression of Methionine Sulfoxide Reductases A and B2 Protects MOLT-4 Cells Against Zinc-Induced Oxidative Stress. Antioxid Redox Sign, 2009,11(2):215-225

24 Zhang C, Jia PP, Jia YY, et al. Methionine Sulfoxide Reductase A (MsrA) Protects Cultured Mouse Embryonic Stem Cells From $\mathrm{H}_{2} \mathrm{O}_{2}$-Mediated Oxidative Stress, J Cell Biochem, 2010,111(1):94-103

25 Singh MP, Kwak GH, Kim KY, et al. Methionine sulfoxide reductase A protects hepatocytes against acetaminophen-induced toxicity via regulation of thioredoxin reductase 1 expression. Biochem Biophys Res Commun, 2017,487(3):695-701

26 Moskovitz J, Berlett BS, Poston JM, et al. The yeast peptide methionine sulfoxide reductase functions as an antioxidant in vivo. P Natl Acad Sci USA, 1997,94(18):9585-989

27 Moskovitz J, Du F, Bowman CF, et al. Methionine sulfoxide reductase A affects beta-amyloid solubility and mitochondrial function in a mouse model of Alzheimer's disease. Am J Physiol Endocrinol Metab, 2016,310(6):E388-E393

28 Fan H, Wu PF, Zhang L, et al. Methionine sulfoxide reductase A negatively controls microglia-mediated neuroinflammation via inhibiting ROS/MAPKs/ NF-kappaB signaling pathways through a catalytic antioxidant function. Antioxid Redox Signal, 2015, 22(10):832-847 
29 Guan XL, Wu PF, Wang S, et al. Dimethyl sulfide protects against oxidative stress and extends lifespan via a methionine sulfoxide reductase A-dependent catalytic mechanism. Aging Cell, 2017,16(2):226-236

30 Hirche F, Schroder A, Knoth B, et al. Methionineinduced elevation of plasma homocysteine concentration is associated with an increase of plasma cholesterol in adult rats. Ann Nutr Metab, 2006,50(2):139-146

31 Virtanen JK, Voutilainen S, Rissanen TH, et al. High dietary methionine intake increases the risk of acute coronary events in middle-aged men. Nutr Metab Cardiovas, 2006,16(2):113-120

32 Eyre MD, Phillips DE, Evans IM, et al. The nutritional role of S-Methyl-L-cysteine. J Sci Food Agric, 1983,34(7):696-700

33 Takada N, Yano Y, Wanibuchi H, et al. S-methylcysteine and cysteine are inhibitors of induction of glutathione S-transferase placental form-positive foci during initiation and promotion phases of rat hepatocarcinogenesis. Jpn J Cancer Res, 1997,88(5):435442

34 Yeh YY, Liu LJ. Cholesterol-lowering effect of garlic extracts and organosulfur compounds: Human and animal studies. J Nutr, 2001,131(3):989s-993s

35 Hsu CC, Yen HF, Yin MC, et al. Five cysteinecontaining compounds delay diabetic deterioration in Balb/cA mice. J Nutr, 2004,134(12):3245-3249

36 Wassef R, Haenold R, Hansel A, et al. Methionine sulfoxide reductase A and a dietary supplement S-Methyl-L-cysteine prevent Parkinson's-Like symptoms. J Neurosci, 2007,27(47):12808-12816

37 WuPF, XieN,Zhang JJ, et al. Resveratrol preconditioning increases methionine sulfoxide reductases A expression and enhances resistance of human neuroblastoma cells to neurotoxins. J Nutr Biochem, 2013,24(6):1070-1077

$38 \mathrm{Wu}$ WN, Wu PF, Chen XL, et al. Sinomenine protects against ischaemic brain injury: involvement of coinhibition of acid-sensing ion channel 1a and L-type calcium channels. Br J Pharmacol, 2011,164(5):14451459

39 Lindorff-Larsen K, Piana S, Palmo K, et al. Improved side-chain torsion potentials for the Amber ff99SB protein force field. Proteins, 2010,78(8):1950-1958

40 Bulvik B, Grinberg L, Eliashar R, et al. Iron, ferritin and proteins of the methionine-centered redox cycle in young and old rat hearts. Mech Ageing Dev, 2009,130(3):139144
41 Vinokur V, Grinberg L, Berenshtein E, et al. Methioninecentered redox cycle in organs of the aero-digestive tract of young and old rats. Biogerontology, 2009,10(1):4352

$42 \mathrm{Wu} \mathrm{PF}$, Long $\mathrm{LH}$, Zeng $\mathrm{JH}$, et al. Protection of L-methionine against $\mathrm{H} 2 \mathrm{O} 2$-induced oxidative damage in mitochondria. Food Chem Toxicol, 2012,50(8):27292735

43 Long LH, Wu PF, Guan XL, et al. Determination of protein-bound methionine oxidation in the hippocampus of adult and old rats by LC-ESI-ITMS method after microwave-assisted proteolysis. Anal Bioanal Chem, 2011,399(6):2267-2274

44 Lim JC, You Z, Kim G, et al. Methionine sulfoxide reductase $\mathrm{A}$ is a stereospecific methionine oxidase. $\mathrm{P}$ Natl Acad Sci USA, 2011,108(26):10472-10477

45 Tarrago L, Kaya A, Weerapana E, et al. Methionine Sulfoxide Reductases Preferentially Reduce Unfolded Oxidized Proteins and Protect Cells from Oxidative Protein Unfolding. J Biol Chem, 2012,287(29):2444824459

46 Moskovitz J, Maiti P, Lopes DH, et al. Induction of methionine-sulfoxide reductases protects neurons from amyloid beta-protein insults in vitro and in vivo. Biochemistry, 2011,50(49):10687-1097

47 Minniti AN, Arrazola MS, Bravo-Zehnder M, et al. The Protein Oxidation Repair Enzyme Methionine Sulfoxide Reductase A Modulates A beta Aggregation and Toxicity In Vivo. Antioxid Redox Sign, 2015,22(1):48-62

48 Novoselov SV, Kim HY, Hua D, et al. Regulation of selenoproteins and methionine sulfoxide reductases $\mathrm{A}$ and B1 by age, calorie restriction, and dietary selenium in mice. Antioxid Redox Signal, 2010,12(7):829-838

49 Cudic P, Joshi N, Sagher D, et al. Identification of activators of methionine sulfoxide reductases A and B. Biochem Bioph Res Co, 2016,469(4):863-867

50 Malloy VL, Krajcik RA, Bailey SJ, et al. Methionine restriction decreases visceral fat mass and preserves insulin action in aging male Fischer 344 rats independent of energy restriction. Aging Cell, 2006,5(4):305-314

51 Thomas S, Senthilkumar GP, Sivaraman K, et al. Effect of S-Methyl-L-Cysteine on Oxidative Stress, Inflammation and Insulin Resistance in Male Wistar Rats Fed with High Fructose Diet. Iran J Med Sci, 2015,40(1):45-50

(Recevied June 1, 2020; revised June 30, 2020) 